\title{
Reduced endogenous insulin secretion in diabetic patients with low-titer positive antibodies against GAD
}

\author{
Yuichiro Takeuchi', Hiroyuki Ito, Koshiro Oshikiri, Shinichi Antoku, Mariko Abe, \\ Mizuo Mifune, Michiko Togane, Masahiro Kato \\ Department of Diabetes, Metabolism and Kidney Disease, Edogawa Hospital, Tokyo, Japan; \\ *Corresponding Author: takeuchi@edogawa.or.jp
}

Received 17 October 2011; revised 18 November 2011; accepted 29 November 2011

\section{ABSTRACT}

Aim: To investigate the clinical characteristics of diabetic patients with a low-titer positive for the anti-glutamic acid decarboxylase 65 antibody (GAD antibody). Methods: The subjects were 420 diabetic inpatients. The endogenous insulin secretion was estimated on the basis of the $\mathrm{C}$ peptide immunoreactivity from a $24 \mathrm{~h}$ urine collection (UCPR). Clinical variables were compared between patients negative for the GAD antibody (GAD antibody titer $<1.5 \mathrm{U} / \mathrm{mL}$ ), a lowtiter positive GAD antibody (1.5 U/mL $\leq$ GAD antibody titer $<10 \mathrm{U} / \mathrm{mL}$ ) and a high-titer positive GAD antibody (10 U/mL $\leq$ GAD antibody titer). Results: The low and high-titer positive GAD antibodies were found in 25 and 10 patients, respectively. The UCPR was significantly lower in both the patients with a low (37 $\pm 33 \mu \mathrm{g} / 24 \mathrm{~h})$ and high-titer ( $39 \pm 27 \mu \mathrm{g} / 24 \mathrm{~h}$ ) positive GAD antibodies than in those negative for GAD antibodies $(71 \pm 52 \mu \mathrm{g} / 24 \mathrm{~h})$. The uCPR level was significantly lower in the low-titer positive GAD antibody group $(29 \pm 22 \mu \mathrm{g} / 24 \mathrm{~h})$ than in the negative group (67 $\pm 55 \mu \mathrm{g} / 24 \mathrm{~h}$ ) among the patients not taking insulin secretagogues. The difference disappeared in the subjects taking insulin secreagogues. In the stepwise multiple regression analysis, a low-titer positive GAD antibody was independently associated with the UCPR level. Conclusions: Endogenous insulin secretion is reduced in diabetic patients positive for GAD antibodies, even if the titer is low. Earlier initiation of insulin therapy might therefore protect the pancreatic $\beta$-cell function in diabetic patients with a low-titer positive GAD antibody.

Keywords: GAD Antibody; Endogenous Insulin
Secretion; Urinary C-Peptide; SPIDDM; LADA

\section{INTRODUCTION}

Glutamic acid decarboxylase (GAD) is a major autoantigen involved in the pathogenesis of type 1 diabetes mellitus, and is clearly associated with a cell-mediated immune response [1]. A subgroup of patients with type 2 diabetes mellitus has circulating autoantibodies to GAD [2-4]. This type of diabetes, which develops during adulthood and progresses insidiously, is referred to as slowly progressive insulin-dependent diabetes (SPIDDM) or latent autoimmune diabetes in adults (LADA). It is distinguished from common type 2 diabetes by the presence of pancreas-specific autoantibodies in the serum. Clinically, early-stage SPIDDM or LADA is sometimes classified as type 2 diabetes. After receiving oral hypoglycemic agents (OHAs) for several months to years, most patients with SPIDDM or LADA require insulin therapy. The presence of antibodies against GAD (GAD antibodies) is a sensitive and specific marker for future insulin dependency in such patients [3-7]. A high titer of GAD antibodies is a common feature in insulin-dependent diabetics, including those with SPIDDM or LADA $[8,9]$.

Diabetic patients showing low positive GAD antibody titers are often encountered in clinical practice. However, the importance of low-titer positivity in term of the GAD antibodies remains largely unexplored. We therefore examined the clinical characteristics of diabetic patients showing low positive GAD antibody titers.

\section{PATIENTS AND METHODS}

\subsection{Patients}

A total of 420 Japanese diabetic inpatients were selected for the study from 466 subjects who underwent a 13-day, in-hospital, diabetes education program at our 
hospital between October 2006 and September 2010. We excluded 46 patients because their GAD antibodies and/ or C-peptide immunoreactivity in 24 hour urine collection (uCPR) were not measured. None of the patients had infections that would potentially influence insulin resistance. The patients were divided into insulin secretagogue $(n=231)$ and non-insulin secretagogue $(n=$ 189 ) groups according to their use of insulin secretagogues, such as sulfonylureas, glinides and/or dipeptidyl peptidase-4 inhibitors. The HbAlc levels were determined by a high performance liquid chromatography method using an automated HLC-723G7 analyzer (Tosoh Corporation, Tokyo, Japan) and were calibrated by the Japan Diabetes Society (JDS) standard calibrators. The value for $\mathrm{HbA1c}(\%)$ was estimated as a National Glycohemoglobin Standardization Program (NGSP) equivalent value $(\%)$ calculated by the formula: $\mathrm{HbAlc}=$ HbA1c (JDS) + 0.4, considering the relational expression of HbAlc (JDS) measured by the previous Japanese standard substance and measurement methods and the HbA1c (NGSP) [10]. The estimated glomerular filtration rate (eGFR) was calculated using the formula reported by Matsuo et al. [11]. This equation originated from the MDRD study group [12] arranged for Japanese individuals, and it is recommended by the Japanese Society of Nephrology: eGFR $\left(\mathrm{mL} / \mathrm{min} / 1.73 \mathrm{~m}^{2}\right)=194 \times \mathrm{Scr}^{-1.094} \times$ Age $^{-0.287} \times 0.739$ (if female).

\subsection{Assays for Gad Antibodies and the Urinary C-Peptide Concentrations}

Biochemical assays for the GAD antibody and uCPR were performed by SRL Co. (Tokyo, Japan). The GAD antibody titer was analyzed by an immunoprecipitation radioligand assay using a Cosmic kit (Cosmic Co., Tokyo, Japan) according to the manufacturer's instructions [13]. The detection limit of the assay was $0.3 \mathrm{U} / \mathrm{mL}$, and the reference value of the GAD antibody titer was less than $1.5 \mathrm{U} / \mathrm{mL}$.

The patients were classified into three groups according to the titer of GAD antibody; a negative GAD antibody (GAD antibody titer $<1.5 \mathrm{U} / \mathrm{mL}$ ), a low-titer positive GAD antibody $(1.5 \mathrm{U} / \mathrm{mL} \leq \mathrm{GAD}$ antibody titer $<10$ $\mathrm{U} / \mathrm{mL})$, and a high-titer positive GAD antibody (10 $\mathrm{U} / \mathrm{mL} \leq \mathrm{GAD}$ antibody titer) group.

\subsection{Statistical Analysis}

The data are shown as the means \pm SD. The clinical characteristics were compared by two-tailed unpaired $t$-tests or a one-way analysis of variance for continuous variables, and $\chi^{2}$ tests for categorical variables. A univariate analysis was performed to investigate the correlations between two independent continuous variables. A stepwise multiple regression analysis was performed to evaluate the associations of the uCPR level with other clinical variables. Differences with $P$ values $<0.05$ were considered to be statistically significant. The statistical software package JMP, version 8.0 (SAS Institute, Cary, NC, USA) was used to perform all analyses.

\section{RESULTS}

There were $25(6 \%)$ and $10(2 \%)$ individuals showing low and high positive GAD antibody titers within the population of diabetic patients. The patients who were positive for GAD antibodies were significantly more common within the population of 95 patients who were receiving insulin therapy ( 3 high-titer and 11 low-titer positives) than in the 325 patients without insulin therapy (7 high-titer and 14 low-titer positives).

Table 1 shows the clinical characteristics of the patients in the groups divided by their GAD antibody titers. Women and patients receiving insulin treatment were more common in the positive GAD antibody groups. The duration of diabetes was significantly shorter in the hightiter positive GAD antibody group than in the negative and low-titer positive GAD antibody group. The levels of HbA1c and eGFR were significantly elevated in the high titer-positive GAD antibody group than in the other groups.

The uCPR level was significantly higher in men than in women $(78 \pm 55$ vs. $54 \pm 40 \mu \mathrm{g} / 24 \mathrm{~h}, P<0.01)$. It was also significantly elevated in the patients using insulin secretagogues $(n=231,73 \pm 49 \mu \mathrm{g} / 24 \mathrm{~h})$ compared to those who were not $(n=189,63 \pm 53 \mu \mathrm{g} / 24 \mathrm{~h}, P=0.03)$. In the univariate analyses, the uCPR level correlated with the age $(\mathrm{r}=-0.26, P<0.01)$, duration of diabetes mellitus $(r=-0.230, P<0.01)$, body mass index $(r=0.27, P$ $<0.01)$, and eGFR level $(r=0.23, P<0.01)$ of the patients.

Figure 1 shows a comparison of the uCPR levels among the negative, low- and high-titer positive GAD antibody groups. The level was significantly reduced in both the low- $(37 \pm 33 \mu \mathrm{g} / 24 \mathrm{~h})$ and high-titer $(39 \pm 27$ $\mu \mathrm{g} / 24 \mathrm{~h}$ ) positive GAD antibody groups than in the negative group $(71 \pm 52 \mu \mathrm{g} / 24 \mathrm{~h})$. When the patients were subgrouped according to gender, the uCPR level also significantly decreased in both the female low-titer (23 \pm $17 \mu \mathrm{g} / 24 \mathrm{~h}, n=12)$ and high-titer $(27 \pm 15 \mu \mathrm{g} / 24 \mathrm{~h}, n=6)$ positive GAD antibody groups compared to the negative GAD antibody group $(57 \pm 41 \mu \mathrm{g} / 24 \mathrm{~h}, n=155, P<$ $0.01)$. The uCPR levels were not significantly different among the male negative $(80 \pm 56 \mu \mathrm{g} / 24 \mathrm{~h}, n=230)$, lowtiter $(51 \pm 39 \mu \mathrm{g} / 24 \mathrm{~h}, n=13)$ and high-titer $(57 \pm 32$ $\mu \mathrm{g} / 24 \mathrm{~h}, n=4$ ) positive GAD antibody groups, although a similar trend was observed.

After the division the patients according to their use of insulin secretagogues, the uCPR level was found to be 
Table 1. The clinical characteristics of the patients in the groups divided by the GAD antibody titers.

\begin{tabular}{|c|c|c|c|c|}
\hline & Negative & Low-titer positive & High-titer positive & \multirow{2}{*}{$P$} \\
\hline & $(n=385)$ & $(n=25)$ & $(n=10)$ & \\
\hline Age (years) & $62.8 \pm 12.3$ & $61.1 \pm 14.6$ & $53.3 \pm 19.2^{* *}$ & 0.11 \\
\hline Women (\%) & 40 & 48 & 60 & $<0.01$ \\
\hline Duration of diabetes (years) & $10.0 \pm 9.5$ & $10.8 \pm 9.5$ & $4.7 \pm 12^{* \#}$ & 0.21 \\
\hline Body mass index $\left(\mathrm{kg} / \mathrm{m}^{2}\right)$ & $25.6 \pm 5.2$ & $25.3 \pm 5.4$ & $22.7 \pm 4.5^{*}$ & 0.21 \\
\hline Fasting plasma glucose $(\mathrm{mg} / \mathrm{dL})$ & $171.9 \pm 57.1$ & $174.6 \pm 76.1$ & $163.5 \pm 64.1$ & 0.88 \\
\hline HbA1c (\%) & $9.8 \pm 2.0$ & $9.7 \pm 2.6$ & $12.0 \pm 3.2^{* * \# \# \#}$ & $<0.01$ \\
\hline $\mathrm{eGFR}\left(\mathrm{mL} / \mathrm{min} / 1.73 \mathrm{~m}^{2}\right)$ & $66.9 \pm 22.7$ & $61.2 \pm 25.1$ & $95.7 \pm 47.7^{* * * \# \#}$ & $<0.01$ \\
\hline Insulin treatment (\%) & 21 & 44 & 30 & $<0.01$ \\
\hline
\end{tabular}

eGFR: estimated glumerular filtration rate. ${ }^{*} P<0.1,{ }^{* *} P<0.05$ and ${ }^{* * *} P<0.01$ vs. negative, ${ }^{*} P<0.1$ vs. negative (unpaired $t$-test); ${ }^{\#} P<0.1$ and ${ }^{\# \# \#} P<0.01$ vs. low-titer positive (unpaired $t$-test).

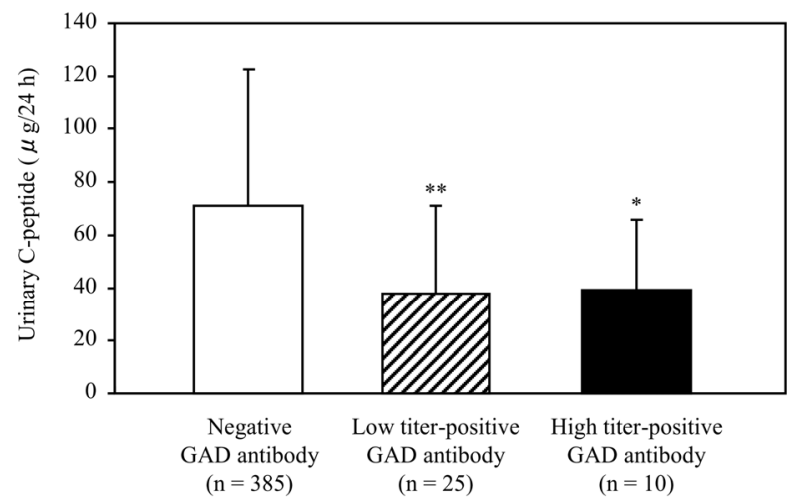

Figure 1. A comparison of the $\mathrm{UCPR}$ levels among the negative, low- and high-titer positive GAD antibody groups. ${ }^{*} P<0.05$ and ${ }^{* *} P<0.01$ vs. the negative GAD antibody group.

significantly lower in the low-titer positive GAD antibody group $(29 \pm 22 \mu \mathrm{g} / 24 \mathrm{~h})$ than in the negative group $(67 \pm 55 \mu \mathrm{g} / 24 \mathrm{~h})$ among the patients in the non-insulin secretagogues subgroup (Figure 2). On the other hand, the significant difference disappeared between the two groups $(51 \pm 44$ and $74 \pm 49 \mu \mathrm{g} / 24 \mathrm{~h})$ in the patients using insulin secretagogues.

A stepwise multiple regression analysis was conducted to examine the clinical variables related to the $\mathrm{uCPR}$ (Table 2). The low-titer positive GAD antibody was independently associated with the level of uCPR.

\section{DISCUSSION}

In the present study, $8 \%$ of the study subjects were positive for GAD antibodies. Individuals who were positive for the GAD antibody were significantly more common in the group receiving insulin therapy $(15 \%)$ than in the group of patients who were not $(6 \%)$. This frequency

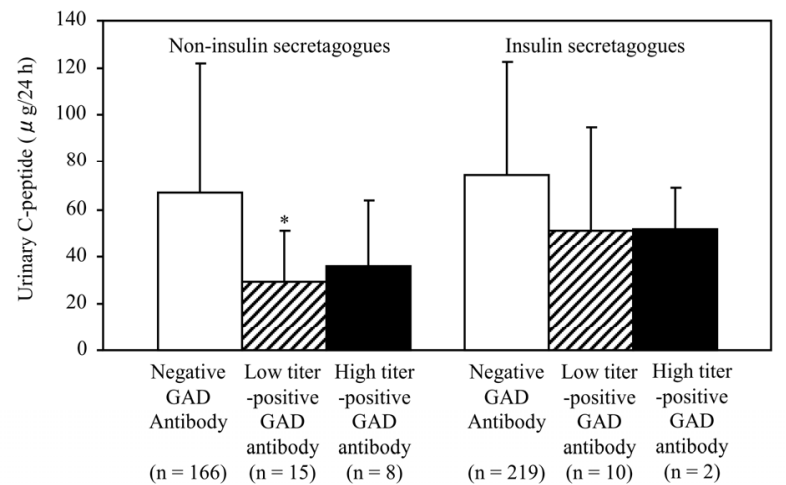

Figure 2. Comparisons of the uCPR levels among the negative, low- and high-titer positive GAD antibody groups after the division of patients according to their use of insulin secretagogues. ${ }^{*} P<0.01$ vs. negative GAD antibody group.

Table 2. The associations between the uCPR and clinical variables as determined by a stepwise multivariate regression analysis.

\begin{tabular}{cccc}
\hline Variables & $F$ & $R^{2}$ & $P$ \\
\hline Duration of diabetes & 33.4 & 0.11 & $<0.01$ \\
Body mass index & 47.9 & 0.06 & $<0.01$ \\
Sex & 28.2 & 0.05 & $<0.01$ \\
eGFR & 19.8 & 0.04 & $<0.01$ \\
Use of insulin secretagogues & 13.0 & 0.03 & $<0.01$ \\
GAD antibody positivity & 7.6 & 0.01 & $<0.01$ \\
\hline
\end{tabular}

eGFR: estimated glomerular filtration rate. The independent variables were as follows: Age (years old), sex $(\operatorname{men}=1$, women $=2)$, duration of diabetes (years), body mass index $\left(\mathrm{kg} / \mathrm{m}^{2}\right)$, eGFR $\left(\mathrm{mL} / \mathrm{min} / 1.73 \mathrm{~m}^{2}\right)$, use of insulin secretagogues (yes $=1$, no $=2$ ), and GAD antibody positivity (negative $=1$, low titer-positive $=2$ ). 
is similar to the previous reports in the Japanese population $[14,15]$. The uCPR levels were lower in both the low- and high-titer positive GAD groups than in the negative GAD group. Furthermore, a low-titer positive GAD antibody was independently associated with the $\mathrm{uCPR}$ in the multiple regression analysis. A low-titer positive GAD antibody might therefore be a potential predict or of insufficient endogenous insulin secretion, similar to a high-titer positive GAD antibody.

Kasuga et al. demonstrated that the titer of GAD antibodies was significantly higher in patients who required insulin treatment $(199 \mathrm{U} / \mathrm{mL})$ than in those who did not (5.8 U/mL) among $43 \mathrm{GAD}$ antibody positive diabetic subjects. A higher titer of GAD antibodies $(\geq 10 \mathrm{U} / \mathrm{mL})$ was also detected in a higher proportion of patients requiring insulin than in those not requiring insulin [16]. Buzzetti et al. also reported that diabetic patients showing a high titer of

GAD antibodies were common in the subjects with insulin deficiency [7]. Kulmala et al. observed 53 children with detectable titers of GAD antibody for 9 years and found that the GAD antibody titer was higher in subjects who progressed to an insulin-dependent state than in those who did not [17]. Tuomi et al. described a negative correlation between the fasting serum C-peptide concentration and the titer of GAD antibody [18]. In contrast, Maruyama et al. reported that the earlier initiation of insulin therapy prevented the progression to insulin-dependent stage compared with the administration of sulfonylureas in patients with low-titer positive GAD antibodies, even if the endogenous insulin secretion was preserved [19]. This suggested the possibility of the slow deterioration of insulin secretion in patients with lowtiter positive GAD antibodies. In the present study, the uCPR level was not different between the low- and high-titer positive GAD antibody groups, although the duration of diabetes was significantly shorter in the patients in the high-titer positive GAD antibody group than in those with low-titer positivity (Table 1).

The uCPR level was significantly higher in men than in women in the present study. After subgrouping the patients according to gender, the uCPR level was found to be significantly lower in both the low- and high-titer positive GAD antibody groups compared to the negative GAD antibody group only in women. However, a similar trend was also observed in men. The lack of a statistically significant difference might have been caused by the small number of the subjects showing positive GAD antibodies in our study.

The uCPR level was significantly increased in the patients who received insulin secretagogues in the present study. Although the uCPR level in the low-titer positive GAD antibody group was not different between the noninsulin and insulin secretagogue groups, the significant difference in the uCPR disappeared between the negative and low-titer positive GAD antibody groups in the noninsulin secretagogure group compared to the insulin secretagogue group (Figure 2). The response to the insulin secretagogues might thus have been preserved in the group with a low-titer positive GAD antibody in our study.

Our study had several important limitations. First, it was a small, cross-sectional study that was unable to show a causal relation between the low-titer positive GAD antibody and the uCPR level. Validation of our results and further elucidation of the potential mechanisms involved are therefore essential. Second, the uCPR level was determined only once in a $24 \mathrm{~h}$ urine collection. Although patients with urinary tract infections, which decrease the uCPR level, were excluded from the study, it would have been better to use the mean uCPR levels derived from multiple determinations, because the $\mathrm{UCPR}$ levels can fluctuate.

\section{ACKNOWLEDGEMENTS}

The authors thank Ms. Sakura Yamamoto of the Secretarial Section of Edogawa Hospital for her valuable help in the data collection.

\section{REFERENCES}

[1] Baekkeskov, S., Aanstoot, H.J., Christgau, S., Reetz, A., Solimena, M., Cascalho, M., Folli, F., Richter-Olesen, H. and De Camilli, P. (1990) Identification of the 64K autoantigen in insulin-dependent diabetes as the GABAsynthesizing enzyme glutamic acid decarboxylase. Nature, 347, 151-156. doi:10.1038/347151a0

[2] Tuomi, T., Groop, L.C., Zimmet, P.Z., Rowley, M.J., Knowles, W. and Mackay, I.R. (1993) Antibodies to glutamic acid decarboxylase reveal latent autoimmune diabetes mellitus in adults with a non-insulin-dependent onset of disease. Diabetes, 42, 359-362. doi:10.2337/diabetes.42.2.359

[3] Hagopian, W.A., Karlsen, A.E., Gottsäter, A., LandinOlsson, M., Grubin, C.E., Sundkvist, G., Petersen, J.S., Boel, E., Dyrberg, T. and Lernmark, A. (1993) Quantitative assay using recombinant human islet glutamic acid decarboxylase (GAD65) shows that $64 \mathrm{~K}$ autoantibody positivity at onset predicts diabetes type. The Journal of Clinical Investigation, 91, 368-374.

doi:10.1172/JCI116195

[4] Turner, R., Stratton, I., Horton, V., Manley, S., Zimmet, P., Mackay, I.R., Shattock, M., Bottazzo, G.F. and Holman, R. (1997) UKPDS 25: Autoantibodies to islet cytoplasm and glutamic acid decarboxylase for prediction of insulin requirement in type 2 diabetes. Lancet, 350, 1288-1293. doi:10.1016/S0140-6736(97)03062-6

[5] Gottsatter, A., Landin-Olsson, M., Lernmark, A., Fernlund, P., Sundkvist, G. and Hapopian, W.A. (1995) Glutamic decarboxylase antibody level predicts rate of B-cell declining in adult-onset diabetes. Diabetes Re- 
search and Clinical Practice, 27, 133-140. doi:10.1016/0168-8227(95)01026-A

[6] Willis, J.A., Scot, R.S. and Brown, L.J. (1996) Islet cell antibodies against glutamic acid decarboxylase in newly diagnosed adult-onset diabetes mellitus. Diabetes Research and Clinical Practice, 33, 89-97. doi:10.1016/0168-8227(96)01281-8

[7] Buzzetti, R., Di Pietro, S., Giaccari, A., Petrone, A., Locatelli, M., Suraci, C., Capizzi, M., Arpi, M.L., Bazzigaluppi, E., Dotta, F., Bosi, E. and Non Insulin Requiring Autoimmune Diabetes Study Group (2007) High titer of autoantibodies to GAD identifies a specific phenotype of adult-onset autoimmune diabetes. Diabetes Care, 30, 932-938. doi:10.2337/dc06-1696

[8] De Block, C.E., De Leeuw, I.H., Vertommen, J.J., Rooman, R.P., Du Caju, M.V., Van Campenhout, C.M., Weyler, J.J., Winnock, F., Van Autreve, J., Gorus, F.K. and Belgian Diabetes Registry (2001) Beta-cell, thyroid, gastric, adrenal and coeliac autoimmunity and HLA-DQ types in type 1 diabetes. Clinical and Experimental Immunology, 126, 236-241. doi:10.1046/j.1365-2249.2001.01668.x

[9] Bárová, H., Perusicová, J., Hill, M., Sterzl, I., Vondra, K. and Masek, Z. (2004) Anti-GAD-positive patients with type 1 diabetes mellitus have higher prevalence of autoimmune thyroiditis than anti-GAD-negative patients with type 1 and type 2 diabetes mellitus. Physiological Research, 53, 279-286.

[10] Seino, Y., Nanjo, K., Tajima, N., Kadowaki, T., Kashiwagi, A., Araki, E., Ito, C., Inagaki, N., Iwamoto, Y., Kasuga, M., Hanafusa, T. and Haneda, M. (2010) Report of the committee on the classification and diagnostic criteria of diabetes mellitus. Journal of Diabetes Investigation, 1, 213-228.

[11] Matsuo, S., Imai, E., Horio, M., Yasuda, Y., Tomita, K., Nitta, K., Yamagata, K., Tomino, Y., Yokoyama, H. and Hishida, A. (2009) Revised equations for estimated GFR from serum creatinine in Japan. American Journal of Kidney Diseases, 53, 982-992. doi:10.1053/j.ajkd.2008.12.034

[12] Coresh, J., Astor, B.C., Greene, T., Eknoyan, G. and Levey, A.S. (2003) Prevalence of chronic kidney disease and decreased kidney function in the adult US population: Third national health and nutrition examination survey. American Journal of Kidney Diseases, 41, 1-12. doi:10.1053/ajkd.2003.50007
[13] Ohta, M., Obayashi, H., Takahashi, K., Kitagawa, Y., Nakano, K., Matsuo, S., Nishimura, M., Itoh, N. and Ohta, K. (1996) Radioimmunoprecipitation assay for glutamic acid decarboxylase antibodies evaluated clinically with sera from patients with insulin-dependent diabetes mellitus. Clinical Chemistry, 42, 1975-1978.

[14] Fukui, M., Nakano, K., Shigeta, H., Yoshimori, K., Fujii, M., Kitagawa, Y., Mori, H., Kajiyama, S., Nakamura, N., Abe, N., Obayashi, H., Fukui, I., Ohta, K., Ohta, M. and Kondo, M. (1997) Antibodies to glutamic acid decarboxylase in Japanese diabetic patients with secondary failure of oral hypoglycaemic therapy. Diabetic Medicine, 14, 148-152.

doi:10.1002/(SICI)1096-9136(199702)14:2<148::AID-DI A317>3.0.CO;2-9

[15] Fukui, M., Nakamura, N., Nakano, K., Sawada, M., Aoji, O., Obayashi, H., Shigeta, H. and Kondo, M. (1998) Antibodies to GAD in elderly patients with previously diagnosed NIDDM. Diabetes Care, 21, 675-676. doi:10.2337/diacare.21.4.675

[16] Kasuga, A., Maruyama, T., Nakamoto, S., Ozawa, Y., Suzuki, Y. and Saruta, T. (1999) High-titer autoantibodies against glutamic acid decarboxylase plus autoantibodies against insulin and IA-2 predicts insulin requirement in adult diabetic patients. Journal of Autoimmunity, 12, 131135. doi:10.1006/jaut.1998.0261

[17] Kulmala, P., Savola, K., Petersen, J.S., Vähäsalo, P., Karjalainen, J., Löppönen, T., Dyrberg, T., Akerblom, H.K. and Knip, M. (1998) Prediction of insulin-dependent diabetes mellitus in siblings of children with diabetes. A population-based study. The childhood diabetes in Finland study group. The Journal of Clinical Investigation, 101, 327-333. doi:10.1172/JCI119879

[18] Tuomi, T., Carlsson, A., Li, H., Isomaa, B., Miettinen, A., Nilsson, A., Nissén, M., Ehrnström, B.O., Forsén, B., Snickars, B., Lahti, K., Forsblom, C., Saloranta, C., Taskinen, M.R. and Groop, L.C. (1999) Clinical and genetic characteristics of type 2 diabetes with and without GAD antibodies. Diabetes, 48, 150-157. doi: $10.2337 /$ diabetes.48.1.150

[19] Maruyama, T., Tanaka, S., Shimada, A., Funae, O., Kasuga, A., Kanatsuka, A., Takei, I., Yamada, S., Harii, N., Shimura, H. and Kobayashi, T. (2008) Insulin intervention in slowly progressive insulin-dependent (type 1) diabetes mellitus. The Journal of Clinical Endocrinology and Metabolism, 93, 2115-2121. doi: $10.1210 /$ ic. $2007-2267$

\section{ABBREVIATIONS}

GAD: Glutamic acid decarboxylase

OHAs: oral hypoglycemic agents

uCPR: C-peptide immunoreactivity in 24 hour urine col-

lection

eGFR: estimated glomerular filtration rate 